\title{
Formation of techniques of creative activity in the school course of mathematics
}

\begin{abstract}
The article highlighted the skills that are part of the creative activity and are effectively formed on the material of the school course of mathematics: the nomination and testing of hypotheses; analysis and comparison of various points of view, their assessment; transfer of knowledge and skills to a new situation; modeling of various scenarios, their comparison; composing text on a mathematical or graphical model. We consider the techniques for the formation of selected skills: the use of disputes, discussions, round tables, brainstorming, tasks with an excessive (insufficient) data set, competence-oriented tasks, tasks with an open question, tasks with omissions in conditions.
\end{abstract}

Keywords: creative activity, creativity, creative thinking, school mathematics course, the formation of creative methods, competence-oriented tasks.
Volume 3 Issue I - 2019

\author{
Lydia Gennadyevna Shestakova,' Tatyana \\ Vasilyevna Richter ${ }^{2}$ \\ 'Department of Mathematical and Natural Sciences, Perm State \\ University, Russia \\ ${ }^{2}$ Department of Mathematical and Natural Sciences, Perm State \\ University, Russia
}

\begin{abstract}
Correspondence: Tatyana Vasilyevna Richter, Department of Mathematical and Natural Sciences, Perm State University, Perm,
\end{abstract} Russia, Email tatyanarikhter@mail.ru

Received: January II, 2019 | Published: January 23, 2019

\section{Introduction}

The ongoing changes in the world and society, the growth of information and the expansion of access to it, make demands on the intellectual qualities of a person, his creative abilities and capabilities. Systemic approach, the ability to apply knowledge in different fields of activity, the ability to see the connections between various phenomena, to create something new, to take a weighted decision become crucial. Speaking about creativity, you need to specify the scope of their applications as creativity in art is not the same as cognitive or scientific activity. In this case, we will talk about training activities. Creativity is often associated with an independent discovery, the acquisition of new knowledge and methods of such activity. Great contribution to the study of the problems of the development of creative thinking was made by such psychologists and teachers as D. Bogoyavlenskaya, J. Dewey, V. Krutetsky, I. Lerner, A. Matyushkin, R. L. Mooney, C.W.Taylor, and others. Taylor $\mathrm{CW}^{1}$ considers creativity as a problem solving. Mooney ${ }^{2}$ distinguishes the four main approaches to creativity:

a. The area in which creativity takes place;

b. Creative product;

c. Creative process;

d. Creative personality.

I Ya. Lerner singled out the components of creative abilities from didactic positions: to transfer previously acquired knowledge and skills to a new situation; to see new functions of the object, its structure; to see alternative solutions to the problem and the solution itself. ${ }^{3}$ Kasumova BS, ${ }^{4}$ researching the possibilities of divergent tasks, suggests using such tasks, encouraging divergent ideas and suggestions of students, demonstrating positive samples and examples of the manifestation of creativity of thinking for the development of creative thinking of schoolchildren in different situations. Utemov $\mathrm{VV}^{6}$ considers the possibilities of TSIP for the development of students' creativity in a secondary school. The purpose of this article is to describe the possibilities of the mathematics course for the formation of creative activity of schoolchildren.

\section{Materials and methods}

During the research on the subject, the following set of methods has been used: theoretical analysis of literature, modeling of the content of work with schoolchildren. From the standpoint of organizing work with schoolchildren and the purposeful development of creative techniques R.S. Nemov's point of view on the interconnection between critical and creative thinking is interesting. Calling it competing, the author notes: «A person whose critical tendency is too pronounced focuses on criticism, although he could create, and not bad. On the contrary, the person whose constructive, creative thinking dominates the critical, can't often see shortcomings in his own judgments and assessments». ${ }^{6}$ Sharing this position, following R.S. Nemov, we will repeat that there is only one way out of this contradiction: in the harmonious balance of critical and creative thinking. We will proceed from this position when identifying those skills that are the part of creative activity and, in our opinion, can effectively be formed on the basis of the school course of mathematics.

a. Nomination and testing of hypotheses.

b. Analysis and comparison of different points of view, their evaluation.

c. Transfer of knowledge and skills to a new situation.

d. Modeling of various variants of development of events, their comparison.

e. Compilation of the text on a mathematical or graphical model.

The school course of mathematics has the opportunity to work out ideas about a hypothesis and abilities to work with it. For example, on the basis of examining particular cases (specific tasks, examples), students make assumptions about formulating. Hypotheses about possible ways (receptions) of its decision are expressed at work with the task. Schoolchildren are introduced to the controversial issues of science (hypotheses), for which no single answer has been found at present. There is information about the history of the development of mathematics, revealing the process of the formation of scientific theories: the promotion of various hypotheses (sometimes contradicting to each other), the substantiation of some of them and the refutation of others. The training uses debates, discussions, round tables, the method of «brainstorming». It is necessary to create conditions for free expression of thoughts, to put students in the situations that require the argumentation of their point of view, to generate ideas, to plan fantastic projects, to refute the opponent correctly, to ask questions (including problem ones) and answer them, etc. The «flow of questions» reception will work well. 
The use of tasks with a redundant (insufficient) set of data, competence-oriented tasks that involve the formation of skills to use acquired knowledge and skills in changing situations, has considerable interest from the positions under consideration. Tasks with an open question, assignments with omissions in a condition that provoke pupils to make a mistake, and an irrational way of solving problems will be helpful. It is possible to offer the pupils of grades 7-9 «to help and explain» the fifth graders to solve the problem for the formation of flexibility of thinking and the ability to find different ways of solving the task. For example, such task can be offered: 3 nails and 2 screws weigh $40 \mathrm{~g}$, and 5 nails and 3 screws - 65g. How much does one nail weigh? Schoolchildren are in a situation that the available to them algebraic way of solving isn't yet known to the fifth-grader. Old tasks, ways of doing are actual following them it is desirable to adhere to the rule: we solve it by those means, which were known to the author earlier. In the process of working with these types of tasks, students learn not to approach the described situation formally, but analyze and evaluate it, find and uncover existing contradictions, isolate and investigate various cases. In addition, we draw attention to using the tasks in the learning process of aimed at moving from a mathematical or graphic model to describing the situation in the verbal form. So in relation to text tasks, we can talk about the need to form a correspondence between the three links of the chain (the ability to move from one link to the other two): text; graphical model (diagram, figure, short note); mathematical model.

\section{Results}

The described opportunities of the school course of mathematics for the formation of the ways of creative activity were introduced into work with the schoolchildren in the framework of the functioning of the experimental site (on the basis of the Solikamsk State Pedagogical Institute) for continuing education in 2016-2017 and 2017-2018 school years. Various aspects were investigated in the framework of diplomas of the students of the Department of Mathematical and Natural Sciences Disciplines.

\section{Conclusion}

In general, we can talk about a positive trend in the formation the considered techniques of creative activity of the students. To summarize, we note that almost every academic discipline has the opportunity to form creative thinking in schoolchildren. To achieve this goal, it is necessary to draw the attention of schoolchildren to work with non-standard assignments, projects, to teach to apply knowledge and skills in various situations, to consider different approaches to solving problems, methods of analysis, evaluation, and the identification of regularities.

\section{Acknowledgment}

None.

\section{Conflicts of interest}

The author declares that there is no conflict of interest.

\section{References}

1. Taylor CW. Various Approaches to and Definitions of Creativity. In: Sterberg RJ, Editor. The Nature of Creativity. Cambridge: Cambridge Univ Press. 1988:99-124.

2. Mooney RL. A conceptual model for integrating four approaches to the identification of creative talent. In: Taylor CW, Barron F, Editors. Scientific creativity: its recognition and development. Wiley. 1963;331-340.

3. Lerner IYa. Problem training. Moscow: Pedagogika. 1974. p. 68

4. Kasumova BS. Divergent mathematical problems as a means of development of creativity of thinking of younger schoolchildren: the dissertations summary on competition of a scientific degree of the candidate of pedagogical sciences. Astrakhan. 2010;22.

5. Utemov VV. Development of creativity of primary school students. Solving problems of an open type. Saarbrucken: LAP LAMBERT Academic Publishing GmbH \& Co. KG. KG (Germany). 2012. p. 186.

6. Nemov RS. Psychology: A textbook for students of higher pedagogical educational institutions: in 3 books. Book 1. M: Humanitarian Publishing Center VLADOS. 2014. p. 688. 